\title{
Role of Magnesium Sulphate for Prevention of Postoperative Atrial Fibrillation in Patients Undergoing Open Heart Bypass (CABG) Surgery
}

\author{
ASHIAALI ${ }^{1}$, MD. KAMRULHASSAN ${ }^{1}$, MOSTOFA NURUZZAMAN ${ }^{1}$, SUMSUZZAMAN ${ }^{1}$, \\ MOSTAFIZUR RAHMAN ${ }^{2}$, REZWANUL HOQUE ${ }^{2}$.
}

\author{
${ }^{1}$ Department of Anesthesia, Analgesia and Intensive Care Medicine (Cardiac Anesthesia wing), Bangabandhu Sheikh Mujib \\ Medical University (BSMMU), Dhaka, ${ }^{2}$ Department of Cardiac Surgery, University Cardiac Center, Bangabandhu Sheikh Mujib \\ Medical University, Dhaka²
}

Address for correspondence: Dr. Ashia Ali, Department of Anesthesia, Analgesia and Intensive Care Medicine (Cardiac Anesthesia wing), Bangabandhu Sheikh Mujib Medical University, Dhaka. Email-dr.ashia.ali@gmail.com

\begin{abstract}
:
To assess the role of magnesium sulphate infusion after coronary artery bypass graft (CABG) surgery in preventing atrial arrhythmias that may occur following CABG operation. Cardiac anaesthesia wing of Bangabandhu Sheik Mujib Medical University, Dhaka from 2007 to 2009. Design: Prospective randomized non blined. All patients under going primary CABG surgery and having sinus rhythm before surgery were alternatively randomized into the study or control group. Patient with history of Atrial Fibrillation (AF), Left Atrial (LA) dysfunction, renal-impairment and implanted pace maker were excluded from the study. The patients in the study group received $10 \mathrm{mmol}$ of magnesium (2.47gm) in $10 \mathrm{ml}$ saline intravenously over 10 min after termination of Cardio Pulmonary Bypass (CPB). The end point was development of AF for 10 min or if an episode of AF had to be treated because of symptoms. A total of 60 patients were included in the study 30 in each group. The incident of $A F$ was $14 \%$ in patients who received single dose of magnesium. The patients without magnesium had an AF incidence of $20 \%$ ( $p=0.353)$ not significant. Single dose magnesium infusion does not prevent AF statistically, but the haemodynamic parameters in patients receiving magnesium were more stable during the whole period of observation.
\end{abstract}

\section{Introduction:}

Post operative arrhythmias are a commonly faced and serious complication of open heart surgery. After CABG surgery the post operative stay in ICU is often complicated by atrial fibrillation (AF) in up to $40 \%$ of cases $^{1}$.

The incidence of postoperative supraventricular arrhythmias has been reported to be $11 \%-54 \%$ and the incidence of ventricular arrhythmia to be $1.8 \%-13 \%{ }^{2}$.

AF may start immediately after surgery which usually becomes prominent during first 48 hours following open heart surgery. AF at this time leads to prolonged occupation of ICU beds and apprehension for the surgeons and intensivists on account of its effect on haemodynamics with a risk of thromoembulism ${ }^{3}$. The aetiology of post operative AF probably is multifactorial. Magnesium has been shown to be effective in reducing the incidence of AF in these patients.

The large majority of arrhythmia cases in CABG surgery except insufficient revascularization can be controlled by electrical cardio version. However, most medications currently used include beta blockers, amioderone have some side effects.
The decrease in the concentrations of ions such as potassium and magnesium during the post operative period is an important factor in most of the cases of arrhythmia that do not have organic causes (that is e.g. insufficient revascularization and graft thrombosis) identifying these ionic imbalance may protect the heart from the side effects of anti-arrhythmia treatments.

Among the physiological ions, magnesium plays an important role in preserving cardiac rhythm by stabilizing membrane function. Thus the aim of our study was to observe the effect of magnesium for prevention and treatment of AF following CABG.

\section{Materials and Methods:}

This was a prospective, randomized controlled, non blined study conducted in the anesthesia wing of university cardiac centre, BSMMU, Dhaka.

All patients undergoing initial CABG, and having sinus rhythm before surgery, were alternatively randomized into the study group or in to the control group. Patient with previous history of AF, implanted pace makers, those suffering from post operative myocardial infarction and 
pre operative renal insufficiency were excluded from the study.

The patients in the study group received $10 \mathrm{mmol}$ of magnesium sulphate (2.47gm) dissolved in $10 \mathrm{ml}$ normal saline infused intravenously over 10mins, after the termination of $\mathrm{CPB}$, whereas the control group received $10 \mathrm{ml}$ normal saline only.

The anaesthesia and surgical procedures were standardized for all patients. Pre operative clinical information and patient demographies were grossly similar. During the post operative period potassium replacements and calcium replacements were administered in ordered to maintain potassium and calcium within normal limits.

In order to standardize the groups, patients were grouped based on following parameters: age, gender, use of calcium channel blockers, use of beta blockers, presence of diabetes, presence of renal disorder, history of myocardial infraction, NYHA classification, cross clamp time, cardio pulmonary bypass duration and number of disease vessels. Any side effects of magnesium were also noted (bradycardia, hypotension).

The logical end point of this study was the development of AF after surgery. Based on previous studies, this was considered significantly, if it continued for at least 10 minutes or more, or if an episode of AF had to be treated because of symptoms or haemodynamic instability ${ }^{4}$.

Data was recorded and analyzed using SPSS-12. The results are presented as Mean \pm SD or percent of patients. A pvalue of $<0.05$ is considered to show statistical significance.

\section{Table-I}

Pre operative and demographic characteristics of the patients in the study sample

\begin{tabular}{lccc}
\hline & $\begin{array}{c}\text { Group 1 } \\
(\mathrm{Mg}, \mathrm{n}=30)\end{array}$ & $\begin{array}{c}\text { Group 2: } \\
(\text { Saline, } \mathrm{n}=30)\end{array}$ & P value \\
\hline Age & $51 \pm 7$ & $53 \pm 6$ & $\mathrm{NS}$ \\
Sex(M/F)\% & $90 / 10$ & $93 / 7$ & NS \\
History of MI & $15(50 \%)$ & $13(47 \%)$ & NS \\
$\begin{array}{l}\text { Hypertension } \\
\text { Pre operative use of }\end{array}$ & $11(36.7 \%)$ & $5(16.7 \%)$ & NS \\
beta blocker & & & \\
Calcium channel & $15(50 \%)$ & $14(48 \%)$ & NS \\
blocker & & & \\
Ejection fraction & $52 \pm 8$ & $51 \pm 7$ & NS \\
$\begin{array}{l}\text { Diabetes mellitus } \\
\text { Side effects of Mg }\end{array}$ & $16(53.3 \%)$ & $19(63 \%)$ & NS \\
Atrial Fibrillation & None & Not administered & \\
\hline
\end{tabular}

*NS: Not significant

\section{Results:}

There were a total of 60 patients who fulfilled the criteria included in the study, 30 in each group. There were no differences regarding age, sex, number of diseased vessels, ejection fraction, NYHA grades, cross clamp durations, use of inotropes, duration of intubation, and duration of stay in ICU and overall length of hospital stay.

LIMA was used for LAD bypass in all patients, while all other anastomosis was performed using saphenous vein graft. The mean number of grafts used was $3.1 \pm 1.2$ in Group 1, $3.2 \pm 1.4$ in Group 2 and these means were not significantly different.

In this study the incidence of AF was 14\% in patients who received magnesium infusion. In contrast, the patients without Magnesium, had an overall incidence of 20\% (pvalue $0.353 \mathrm{NS}$ ). The AF which occurred post operatively was treated with amiodarone infusion and all patients recovered normal sinus rhythm.

Table-II

Per operative and post operative patient data

\begin{tabular}{lccc}
\hline & Group 1 & Group 2 & p- value \\
\hline LIMA uses & $30(100 \%)$ & $30(100 \%)$ & NS \\
$\begin{array}{l}\text { Saphenous graft } \\
\text { Mean number } \\
\text { of grafts }\end{array}$ & $3.1 \pm 1.2$ & $3.3 \pm 1.4$ & NS \\
$\begin{array}{l}\text { Durations of } \\
\text { intubations (hours) }\end{array}$ & $16.6 \pm 4$ & $15.5 \pm 3.5$ & NS \\
$\begin{array}{l}\text { Discharge time(days) } \\
\text { Cross clamp }\end{array}$ & $8 \pm 1$ & $8 \pm 2$ & NS \\
time(minute) & $90 \pm 25$ & $91 \pm 23$ & NS \\
Inotrope support & $13(37 \%)$ & $11(32 \%)$ & NS \\
\hline
\end{tabular}

NS, not significant $(\mathrm{p}>0.05)$

\section{Discussions:}

$\mathrm{AF}$ is an undesired but frequent complication of CABG observed in $10-40 \%$ of cases. The incidence of supra ventricular arrhythmia ranges from 40-47\% whereas ventricular arrhythmia is $34 \%$ after open heart surgery ${ }^{5}$. There are reports suggesting that magnesium reduces the incidence of ventricular arrhythmia and supra ventricular arrhythmia including AF.

Exact cause of AF is unknown but aortic cross clamping and inflammatory response during bypass is considered to be a factor in the development of AF. Atrial ischemia due to possible kinking of grafts or poor myocardial protection might be the other reasons. AF might lead to homodynamic disorders, thromoembulism and prolongs a patient's stay in ICU or hospital. 
Several prophylactic drugs have been used for AF which includes use of magnesium as a single dose, continuous Mg infusion for several days, use of beta blockers, amiodarone and / or diltiazem. But all these drugs have limited success. A meta-analysis by Shiga ${ }^{6}$ and associates concluded that prophylactic $\mathrm{Mg}$ reduces the incidence of AF after CABG in about $20 \%$ of the cases.

Use of prophylactic and continuous infusion is being practiced in several centers. Using Mg greater than 4 grams has been associated with occurrence of bradycardia requiring pacing for 24 hours and mild hypotension which is responsive to fluid administration.

Despite the evidence that the administration of $\mathrm{Mg}$ sulphate can reduce the incidence of post operative cardiac arrhythmia, its use has remained controversial: Parikka et al found that more direct current shocks and higher energy levels were required for defibrillation after CPB in magnesium treated patients, indicating that high intra operative plasma level of $\mathrm{Mg}$ may have adverse effects on the heart. Balser ${ }^{7}$ demonstrated that small dose of postoperative magnesium supplementation reduced the incidence of ventricular arrhythmia, but larger doses of magnesium were needed to prevent AF.

Fanning, Karmy-Jones and associates ${ }^{8}$ could not find any significant differences between treatment and control groups in terms of incidence of atrial fibrillation development. Kaplan ${ }^{9}$ reported supraventricular tachycardia in magnesium and control group in $2 \%$ and $4 \%$ cases respectively and atrial fibrillation in $15 \%$ and $16 \%$ respectively.

In a review article of the physiological and pharmacology of magnesium and its role in anesthetic practice, Fawcett el al $^{10}$ suggested that the main role for magnesium for cardiac surgery consists of myocardial protection and not the prevention of post operative arrhythmia.

The results from the study of this paper also conforms to the findings of Kaplan, Fanning and Fawcett in that statistically significant evidence could not be found to support the claim that Mg use can help prevent in post operative arrhythmia and AF, especially in low dosages.

However, it has been shown that magnesium has analgesic efficacy and reduces the need for post operative analgesics because it acts as a NMDA antagonist and blocks calcium channels. There is controversy in its use, with papers both in favor and against the use of Mg. In spite of differing opinions, there are recent powerful papers which fully support the prophylactic use of $\mathrm{Mg}$ in reduction of AF as well as in reduction of hospital stay.

\section{Conclusion:}

The study shows that a single dose of Mg infusion during operation in patients undergoing CABG surgery does not give any statistically significant evidence of decreasing incidence of AF ( $p>0.05$ ). However, the haemodynamic parameters in patients receiving $\mathrm{Mg}$ was more stable during the whole period of observation.

Even so, using Mg may avoid low post operative levels of $\mathrm{Mg}$ and its concomitant side effects as well as post operative AF. Therefore it is still recommended for use as a membrane stabilizing agent during open heart surgery, without routine measurement of blood levels since it is cheap, safe, easily available and has minimal side effects in low doses.

\section{References:}

1. Mathew JP,Fontes ML,Tudor IC,Ramsay J, Duke p,Mazer Cd.et al. A multicenter risk index for atrial fibrillation after cardiac surgery.JAMA 2004;291;1720-9.

2. Benach M,Rysz j,Drozdz JA,OkonskiP, Misztal M,Barylski M,Irzmanski R,Zaslonka J: Risk factors of atrial fibrillation following coronary artery bypass grafting: a preliminary report. Circ J2006, 70(4); 438-41.

3. Toraman F,Karabulut EH,Alhan C,Dagdelen S, Tarcan S: Magnesium infusion dramatically decreases the incidence of atrial Fibrillation after coronary artery bypass grafting. Ann Thorac surg 2001; 72:1256-62

4. Kohno H, Koyanagi T, Kasegawa H, Miyazaki M. Three-day magnesium administration prevents atrial fibrelation after coronary artery bypass grafting. Ann Thorac Surg 2005, 79; 117-26

5. England Mr,Gordon G,Salem M \&Chernow B. Magnesium administration and dysrrthmias after cardiac surgery. A placebo controlled, double blind, randomized trial. JAMA 1992; 268:2395-402

6. Shiga T, Wajima J, Inoue T \& Ogawa R. Magnesium prophylaxis for arrhythmias after cardiac surgery: a metaanalysis of randomized controlled trials. Am J Med 2004; 117:325-33.

7. Balser JR.Pro: All patients should received pharmacologic prophylaxis for atrial fibrillation after cardiac surgery. J Cardiothoracic vasc Anesth 1999; 13:98-100.

8. Fanning WJ,ThomasCS Jr@ Roach A. Prophylaxis of atrial fibrillation with magnesium sulphate after coronary artery bypass grafting. Ann Thorac surg 1991; 52:529-33

9. Kaplan M, Kut MS,Icer UA,Demirtas MM. Intravenous magnesium sulphate prophylaxis atrial fibrillation after coronary artery bypass surgery. J Thorac cardiovasc surg 2003; 125:344-352.

10. Fawcett WJ, Haxby EJ \& Male DA. Magnessium: physiology and pharmacology. Br J Anaesth 1999; 83 : 302 - 320 